\title{
Thermo-economic assessment of three-stage combined cycle power system using ammonia-water mixture
}

\author{
Amin Momeni ${ }^{1, a}$, Pouria Ahmadi ${ }^{2}$, Halil S. Hamut ${ }^{3}$ And Mehdi Ashuaee ${ }^{1}$ \\ 1 School of Mechanical Engineering, College of Engineering, University of Tehran, Tehran, Iran \\ 2 School of Engineering Science, School of Mechatronic System Engineering, Simon Fraser University, Vancouver, Canada \\ ${ }^{3}$ Scientific and Technological Research Council of Turkey, Marmara Research Center, Energy Institute, Kocaeli, Turkey
}

Received 19 April 2015, Accepted 22 October 2015

\begin{abstract}
Thermo-economic modeling and multi-objective optimization studies are performed for a threestage combined cycle system using ammonia water mixture as working fluid. This combined cycle plant is composed of three main subsystems, Brayton cycle, Rankine and Kalina cycles. Energy and exergy analyses and multi-objective optimization are included. In order to optimize the system, a multi-objective optimization method based on a fast and elitist non-dominated sorting genetic algorithm is applied to determine the best design parameters of the system. The two objective functions considered for the optimization purpose are the total cost rate of the system including equipment costs, and the second objective function is the system exergy efficiency. The total cost rate of the system is minimized while the cycle exergy efficiency is maximized using an evolutionary algorithm. In order to convey a deeper understanding and identify the necessary trade-offs within the optimized objectives in a multifaceted fashion, multi-objective optimizations are conducted in the study. Moreover, a closed form equation is derived to provide the relationship between the exergy efficiency and total cost rate. Finally, sensitivity analyses are performed to better understand the effects of various key design parameters on the total exergy destruction rate, exergy efficiency and total cost rate of the system.
\end{abstract}

Key words: Efficiency / exergy / three-stage cycle / energy / multi-objective optimization

\section{Introduction}

The demand for more efficient power generation systems has been strongly increased due to the importance of energy resource limitations, adverse environmental impact and daily growth of energy consumption. Cascade power cycles are one of the potential ways to enhance the performance of power plants. In such cycles, energy source for the bottom cycle is provided by the outlet energy from the topping cycle. Among the cascade power generation systems, which are proposed to improve the system performance, ammonia-water mixture as an effective working fluid in low temperature and pressure ranges has achieved considerable interest by many engineers and researchers around the world [1].

The first type of the ammonia-water cycle, presented by Kalina [2], was proposed to produce more power than a conventional steam Rankine cycle. Comparing gas engines and gas diesel engines with ammonia-water bottoming cycle was studied by Jonsson and Yan [3]. They concluded

\footnotetext{
${ }^{a}$ Corresponding author: amin_momeni@ut.ac.ir
}

that the high exhaust gas temperature from the gas engines increases the output power of the ammonia-water bottoming cycle in comparison with the Rankine cycle. Srinivas et al. [4] simulated a combined cycle with Kalina bottoming cycle. The results showed that combined cycle efficiency increases with an increase in the turbine inlet pressure and the same decreases with increase in the ambient temperature, turbine inlet temperature and its concentration. Gross efficiency between $13.5 \%$ and $18.8 \%$ was reported by Ogriseck [5] for a Kalina cycle which was integrated with a combined heat and power cycle. Wagar et al. [6] developed a thermodynamic model based on the Rankine cycle with ammonia-water mixture. They also conducted an optimization of the system and the optimization results lead to an increase in system efficiency for about $10 \%$. Shi and Che [7] studied a combined system including Rankine cycle with ammonia-water and the liquid natural gas power generation cycle. The calculated results showed that electrical and energy efficiencies are $33.28 \%$ and $48.87 \%$, respectively. Sun et al. [8] and Lolos and Rogdakis [9] studied the Kalina cycle with solar collectors and auxiliary super heaters. Sun et al. 


\section{Nomenclature}

\begin{tabular}{|ll|}
\hline$A$ & Area $\left(\mathrm{m}^{2}\right)$ \\
$\mathrm{Ex}$ & Exergy flow rate $(\mathrm{kW})$ \\
$h$ & Specific enthalpy $\left(\mathrm{kJ} \cdot \mathrm{kg}^{-1}\right)$ \\
$\dot{m}$ & Mass flow rate $\left(\mathrm{kg} \cdot \mathrm{s}^{-1}\right)$ \\
$\dot{Q}$ & Heat rate $(\mathrm{kW})$ \\
$R_{p}$ & Pressure ratio \\
$S$ & Specific entropy $\left(\mathrm{kJ} \cdot \mathrm{kg}^{-1} \cdot \mathrm{K}^{-1}\right)$ \\
$T$ & Temperature $(\mathrm{K})$ \\
$U$ & Overall heat transfer coefficient $\left(\mathrm{W} \cdot \mathrm{m}^{-2} \cdot \mathrm{K}^{-1}\right)$ \\
$\dot{W}$ & Work rate $(\mathrm{kW})$ \\
$Z$ & Purchase cost $(\$)$ \\
\hline & \\
\hline$\eta$ & Energy efficiency \\
$\Psi$ & Exergy efficiency \\
\hline & \\
\hline avl & Available \\
$\mathrm{B}$ & Brayton cycle \\
$\mathrm{Comp}$ & Compressor \\
$\mathrm{Cond}$ & Condenser \\
$\mathrm{D}$ & Destruction \\
$\mathrm{HE} 1$ & Heat exchanger 1 \\
$\mathrm{HE} 2$ & Heat exchanger 2 \\
$\mathrm{~h}$ & High temperature \\
$\mathrm{K}$ & Kalina cycle \\
$\mathrm{l}$ & low temperature \\
$\mathrm{m}$ & Mean \\
$\mathrm{ph}$ & Physical \\
$\mathrm{R}$ & Rankine cycle \\
recup & Recuperator \\
rev & Reversible \\
tot & Total \\
turb & Turbine \\
$\mathrm{w}$ & Work \\
0 & Dead state \\
\hline & \\
\hline $\mathrm{I}$ & First \\
$\bullet$ & Rate \\
\hline
\end{tabular}

concentrated on the effect of pressure differences on thermal efficiency enhancement. The results indicated that at 2.5 MPa pressure difference, efficiency is $16.3 \%$, where in the Lolos and Rogdakis' study, the maximum efficiency is reported to be $8.3 \%$. Dejfors et al. [10] studied thermodynamic advantages of ammonia-water mixture in small direct-fired biomass fueled cogeneration plants and concluded that net power output of cogeneration system with Kalina cycle is lesser than cogeneration configuration with Rankine cycle. Exergy analysis as a potential tool has attracted several researchers around the world to conduct research due to its fundamental role on addressing the issues such as finding methods to increase the system efficiency and sustainability as well as to answer some critical question such as how to mitigate global warming [11]. Padilla et al. [12] studied a combined power/cooling cycle, which combines the Rankine and absorption refrigeration cycles and uses ammonia-water mixture as the working fluid. The maximum effective first law efficiency was $20 \%$ for the heat source and absorber temperatures of
$170{ }^{\circ} \mathrm{C}$ and $30{ }^{\circ} \mathrm{C}$, respectively. Energy and exergy analyses and environmental impact assessments of integrated organic Rankine cycle for trigeneration were carried out by Ahmadi et al. [13]. The exergy efficiency of the trigeneration system was found to be higher than that of typical combined heat and power systems or gas turbine cycles. They also concluded that increasing the turbine inlet temperature decreases the cost of environmental impact, primarily by reducing the combustion chamber mass flow rate. Exergy analysis of power and refrigeration cogeneration systems with ammonia-water mixture as working fluid was also investigated. Liu and Zhang [14] found that there are certain split fractions which maximize the exergy efficiency for a given basic working fluid concentration. $18.2 \%$ reduction in energy consumption was evaluated in their study in comparison with the conventional separate generation system. Vidal et al. [15] investigated the new combined cycle proposed by Goswami. Solar collectors or waste heat were suggested as heat sources to drive the cycle. Exergy effectiveness was in the range of $51 \%$ and $53 \%$ for the heat input requirements at temperature in the range $125^{\circ} \mathrm{C}$ and $150{ }^{\circ} \mathrm{C}$.

Unlike a wide range of studies conducted for twostage combined cycle, only few of them investigated the performance assessment of three-stage combined cycles. Takeshita et al. [16] proposed a three-stage cogeneration system that recovers power to compensate for change in heat transfer demands. Miyazaki et al. [17] and Marrero et al. [18] investigated the thermodynamics analysis of a triplet combined power cycle. Miyazaki et al. considered steam and ammonia as working fluids for middle and bottom stages, respectively, where Marrero et al. used ethane-propane and ammonia-water, respectively. Recently, Momeni and Shokouhmand [19] investigated a three-stage combined cycle power systems utilizing ammonia-water mixture as a working fluid in bottoming cycle. They have concluded that the second law efficiency of the three-stage cycles with variable and constant ammonia fraction are $4.71 \%$ and $5.15 \%$ higher than steamgas combined power cycle, respectively.

In order to have an efficient power generation system, exergy analysis may not always be sufficient when not reinforced by other considerations. Economic in this regard, also plays an imperative role during comprehensive design of power generation systems. Thus, it is important to optimize the studied system in a way that a chosen quantity, known as the objective function, is maximized or minimized accordingly.

Applying optimization techniques based on exergy and cost has introduced itself as a useful tool to address and assist designers to build new power generation systems with both efficiency and total cost perspectives in mind. Among several optimization techniques, evolutionary algorithms have introduced themselves as a good candidate for thermal system design due to the ability to avoid being trapped in local optimal solution like traditional methods and the use of probabilistic selection rules, as opposed to deterministic ones. Ahmadi et al. [20] used evolutionary algorithm to optimize 
a poly-generation energy system. They comprehensively model a poly-generation energy system for the production of electricity, heating, cooling and hot water. They used a multi-objective genetic algorithm to optimize the system. They concluded that gas turbine inlet temperature, compressor pressure ratio and gas turbine isentropic efficiency tend to be at their maximum values indicating that an increase in these parameters results in better system performance. In another study, Ahmadi et al. [21] optimized combined cycle power plants by considering three objective functions: exergy efficiency, total cost rate of the system products and $\mathrm{CO}_{2}$ emissions of the overall plant. The optimization results suggested that environmental impacts can be reduced by selecting the best components and using the low flow rate into the combustion chamber. Thermoeconomic analysis and optimization of an ammonia-water power/cooling cogeneration cycle were carried out by Zare et al. [22]. Results indicated that the sum of the unit costs of the products for the cost optimal design is reduced by around $18.6 \%$ and $25.9 \%$ as compared to that of the thermal efficiency and exergy efficiency optimal designs, respectively. Ahmadi et al. [23] modeled a new multigeneration energy system that produces multiple commodities: power, heating, cooling, hot water and hydrogen. Using an evolutionary algorithm, the total cost of the system was minimized while the cycle exergy efficiency was maximized. They also derived an equation for relationship between exergy efficiency and total cost rate. Modified exergoeconomic model was presented by Coskun et al. [24]. This model was developed for geothermal power plants with the exergy efficiency between $37 \%$ and $48 \%$. Arslan [25] studied Simav geothermal field for electricity generation. Exergoeconomic evaluation showed that with the best design, power generation of $41.2 \mathrm{MW}$, and electricity production of $346.1 \mathrm{GWh} / \mathrm{a}$ can be obtained with an energetic efficiency of $14.9 \%$ and exergetic efficiency of $36.2 \%$. Fu et al. [26] proposed a cascade utilization system including Kalina cycle subsystem and oil production process subsystem. Results demonstrated that the ammonia concentration and the inlet pressure of the turbine should be lower than that of the optimum points in order to ensure the system stability. Thermoeconomic evaluation and optimization of Brayton-Rankine-Kalina combined triple power cycle were investigated by Singh and Kaushik [27]. The objective function considered was the minimization of the total cost rate of the entire plant.

In this paper, a comprehensive thermodynamic model of a three-stage combined cycle power systems is developed. Furthermore, an evolutionary based multi-objective optimization is conducted to optimize the system parameters under different operating conditions for the analyzed system. The specific objectives are as follows:

- To develop a comprehensive model of three-stage combined cycle power systems with constant ammonia fraction at bottoming cycle.

- To apply a multi-objective optimization technique using Matlab software program and genetic algorithm approach.
- To propose a new closed-form expression for the total cost rate in terms of exergy efficiency at the optimal design point.

- To conduct sensitivity analyses for each key design parameter of the system for each objective function.

\section{System description}

Three-stage combined cycle power system consisting of Brayton cycle, Rankine cycle and Kalina cycle is thermodynamically modeled, analyzed and optimized. This three-stage combined system works with constant ammonia concentration, which uses ammonia-water mixture at low temperature as shown in Figure 1. The top stage includes a gas turbine cycle with air as a working fluid; the middle stage includes a steam cycle and the bottom stage includes a Kalina cycle with constant ammonia fraction. The condenser of the steam cycle exchanges heat in higher temperature and pressure to a Kalina cycle. This exchanged heat is considered as a heat source for the bottom stage. In order to perform the thermodynamic modeling of the cycle several assumptions are made in order to render the analysis more traceable:

- Gas turbine inlet temperature is assumed to be $1650 \mathrm{~K}$.

- Turbine and compressor pressure ratios in the Brayton cycle are assumed to be 7 .

- Mass flow rate in the Brayton cycle is considered as $70 \mathrm{~kg} \cdot \mathrm{s}^{-1}$.

- Isentropic efficiency of all turbines in this research study is assumed to be 0.85 .

- Isentropic efficiency of all pumps and the compressors in this research study is considered to be 0.9 .

- Pinch point temperatures difference of all heat exchangers and recuperators are assumed to be $5 \mathrm{~K}$.

- Reference environment temperature and pressure are taken to be $290 \mathrm{~K}$ and $101 \mathrm{kPa}$, respectively.

- Pressure drop and heat loss in pipelines are neglected except for the $3 \%$ pressure drop in the ammonia-water mixture as passing through the heat exchangers and recuperators.

- Low temperature of the cycles is assumed to be $300 \mathrm{~K}$.

- Air and flue gasses in the system are assumed to work based on ideal gas assumption.

\section{Energy analysis}

All components associated with the cycle were steady flow devices. Kinetic and potential energy changes are usually small in comparison with the work and heat transfer terms and are usually negligible. Governing equations and energy balances are divided into three subsections: topping stage (Brayton cycle), middle stage (Rankine cycle) and bottoming stage (Kalina cycle). 


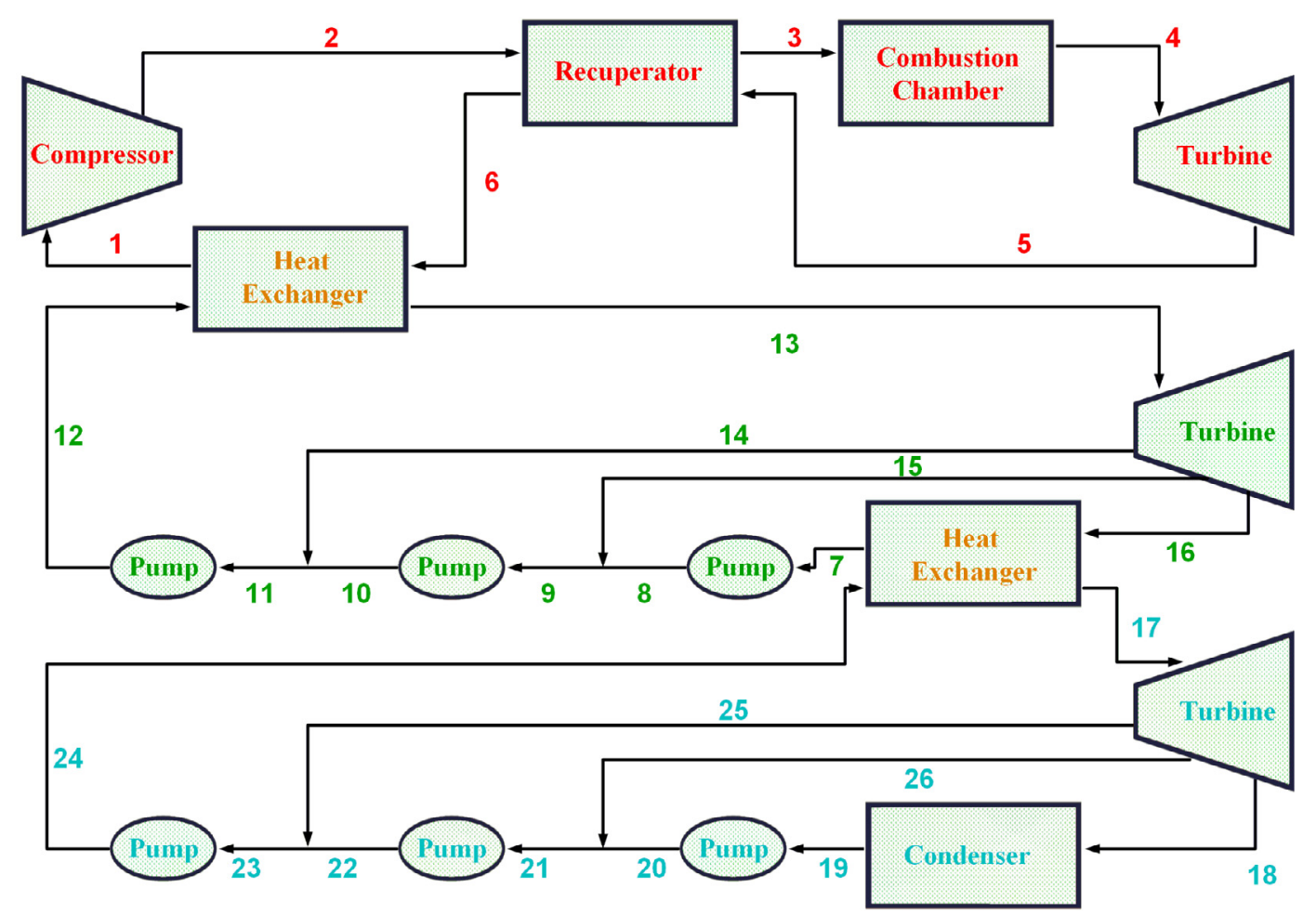

Fig. 1. Schematic of three stage combined cycle.

\subsection{Topping stage (Brayton cycle)}

Isentropic efficiencies for compressor and gas turbine are expressed as follows:

$$
\begin{aligned}
\eta_{\text {comp }, \mathrm{B}} & =\frac{h_{2 s}-h_{1}}{h_{2}-h_{1}} \\
\eta_{\text {turb }, \mathrm{B}} & =\frac{h_{4}-h_{5}}{h_{4}-h_{5 s}}
\end{aligned}
$$

Compressor, turbine and net work of topping stage are expressed as follows:

$$
\begin{aligned}
\dot{W}_{\text {comp, B }} & =\dot{m}_{B}\left(h_{2}-h_{1}\right) \\
\dot{W}_{\text {turb, B }} & =\dot{m}_{B}\left(h_{4}-h_{5}\right) \\
\dot{W}_{\text {net, B }} & =\dot{W}_{\text {turb, B }}-\dot{W}_{\text {comp, B }}
\end{aligned}
$$

Writing the energy balance equation for heat exchangers yields:

$$
\begin{array}{r}
\dot{Q}_{\mathrm{h}, \mathrm{B}}=\dot{m}_{\mathrm{B}}\left(h_{4}-h_{3}\right) \\
\dot{Q}_{1, \mathrm{~B}}=\dot{m}_{\mathrm{B}}\left(h_{6}-h_{1}\right)
\end{array}
$$

The first law efficiency of the topping stage can be expressible as follows:

$$
\eta_{n e t, B}^{\mathrm{I}}=1-\frac{\dot{Q}_{l, B}}{\dot{Q}_{h, B}}=\frac{\dot{W}_{n e t, B}}{\dot{Q}_{h, B}}
$$

\subsection{Middle stage (Rankine cycle)}

Isentropic efficiencies for pumps and steam turbine are expressed as follows:

$$
\begin{aligned}
\eta_{\text {pump1, R }} & =\frac{h_{8 s}-h_{7}}{h_{8}-h_{7}} \\
\eta_{\text {pump2, R }} & =\frac{h_{10 s}-h_{9}}{h_{10}-h_{9}} \\
\eta_{\text {pump3, R }} & =\frac{h_{12 s}-h_{11}}{h_{12}-h_{11}} \\
\eta_{\text {turb }, \mathrm{R}} & =\frac{h_{13}-h_{14}}{h_{13}-h_{14 s}} \\
\eta_{\text {turb }, \mathrm{R}} & =\frac{h_{14}-h_{15}}{h_{14}-h_{15 s}} \\
\eta_{\text {turb }, \mathrm{R}} & =\frac{h_{15}-h_{16}}{h_{15}-h_{16 s}}
\end{aligned}
$$

Heat exchanged between Brayton and Rankine cycles is expressed as follows:

$$
\dot{m}_{B}\left(h_{6}-h_{1}\right)=\dot{m}_{R}\left(h_{13}-h_{12}\right)
$$

Mixers mass balance equations of middle stage are expressed as follows:

$$
\begin{aligned}
\dot{m}_{14}\left(h_{14}-h_{11}\right) & =\left(\dot{m}_{B}-\dot{m}_{14}\right)\left(h_{11}-h_{10}\right) \\
\dot{m}_{15}\left(h_{15}-h_{9}\right) & =\left(\dot{m}_{B}-\dot{m}_{14}-\dot{m}_{15}\right)\left(h_{9}-h_{8}\right)
\end{aligned}
$$


Pumps, turbine and network of middle stage are expressed as follows:

$$
\begin{aligned}
\dot{W}_{\text {pumps, R }}= & \left(\dot{m}_{R}-\dot{m}_{14}-\dot{m}_{15}\right)\left(h_{8}-h_{7}\right) \\
& +\left(\dot{m}_{R}-\dot{m}_{14}\right)\left(h_{10}-h_{9}\right)+\dot{m}_{R}\left(h_{12}-h_{11}\right) \\
\dot{W}_{\text {turb }, \mathrm{R}}= & \dot{m}_{R}\left(h_{13}-h_{14}\right)+\left(\dot{m}_{R}-\dot{m}_{14}\right)\left(h_{14}-h_{15}\right) \\
& +\left(\dot{m}_{R}-\dot{m}_{14}-\dot{m}_{15}\right)\left(h_{15}-h_{16}\right) \\
\dot{W}_{\text {net }, \mathrm{R}}= & \dot{W}_{\text {turb }, R}-\dot{W}_{\text {pumps }, R}
\end{aligned}
$$

Heat exchanged equations for source and sink temperatures of middle stage are expressed as follows:

$$
\begin{aligned}
\dot{Q}_{\mathrm{h}, \mathrm{R}} & =\dot{m}_{R}\left(h_{13}-h_{12}\right) \\
\dot{Q}_{1, \mathrm{R}} & =\left(\dot{m}_{R}-\dot{m}_{14}-\dot{m}_{15}\right)\left(h_{16}-h_{7}\right)
\end{aligned}
$$

The first law efficiency of the middle stage is expressed as follows:

$$
\eta_{\text {net, } \mathrm{I}}^{\mathrm{I}}=1-\frac{\dot{Q}_{l, R}}{\dot{Q}_{\mathrm{h}, \mathrm{R}}}=\frac{\dot{W}_{\mathrm{net}, \mathrm{R}}}{\dot{Q}_{\mathrm{h}, \mathrm{R}}}
$$

\subsection{Bottoming stage (Kalina cycle)}

Isentropic efficiencies for pumps and ammonia-water mixture turbine are expressed as follows:

$$
\begin{aligned}
\eta_{\text {pump } 1, \mathrm{~K}} & =\frac{h_{20 s}-h_{19}}{h_{20}-h_{19}} \\
\eta_{\text {pump } 2, \mathrm{~K}} & =\frac{h_{22 s}-h_{21}}{h_{22}-h_{21}} \\
\eta_{\text {pump }, \mathrm{K}} & =\frac{h_{24 s}-h_{23}}{h_{24}-h_{23}} \\
\eta_{\text {turb }, \mathrm{K}} & =\frac{h_{17}-h_{25}}{h_{17}-h_{25 s}} \\
\eta_{\text {turb }, \mathrm{K}} & =\frac{h_{25}-h_{26}}{h_{25}-h_{26 s}} \\
\eta_{\text {turb }, \mathrm{K}} & =\frac{h_{26}-h_{18}}{h_{26}-h_{18 s}}
\end{aligned}
$$

Heat exchanged between Rankine and Kalina cycles is expressed as follows:

$$
\left(\dot{m}_{R}-\dot{m}_{14}-\dot{m}_{15}\right)\left(h_{16}-h_{7}\right)=\dot{m}_{K}\left(h_{17}-h_{24}\right)
$$

Mixers mass balance equations of bottoming stage are expressed as follows:

$$
\begin{aligned}
& \dot{m}_{25}\left(h_{25}-h_{23}\right)=\left(\dot{m}_{K}-\dot{m}_{25}\right)\left(h_{23}-h_{22}\right) \\
& \dot{m}_{26}\left(h_{26}-h_{21}\right)=\left(\dot{m}_{K}-\dot{m}_{25}-\dot{m}_{26}\right)\left(h_{21}-h_{20}\right)
\end{aligned}
$$

Pumps, turbine and net output power of bottoming stage are expressed as follows:

$$
\begin{aligned}
\dot{W}_{\text {pumps, K }}= & \left(\dot{m}_{K}-\dot{m}_{25}-\dot{m}_{26}\right)\left(h_{20}-h_{19}\right) \\
& +\left(\dot{m}_{K}-\dot{m}_{25}\right)\left(h_{22}-h_{21}\right)+\dot{m}_{K}\left(h_{24}-h_{23}\right) \\
\dot{W}_{\text {turb }, \mathrm{K}}= & \dot{m}_{K}\left(h_{17}-h_{25}\right)+\left(\dot{m}_{K}-\dot{m}_{25}\right)\left(h_{25}-h_{26}\right) \\
& +\left(\dot{m}_{K}-\dot{m}_{25}-\dot{m}_{26}\right)\left(h_{26}-h_{18}\right) \\
\dot{W}_{\text {net }, \mathrm{K}}= & \dot{W}_{\text {turb }, \mathrm{K}}-\dot{W}_{\text {pumps }, \mathrm{K}}
\end{aligned}
$$

Heat exchanged equations for source and sink temperatures of bottoming stage are expressed as follows:

$$
\begin{aligned}
& \dot{Q}_{\mathrm{h}, \mathrm{K}}=\dot{m}_{K}\left(h_{17}-h_{24}\right) \\
& \dot{Q}_{\mathrm{l}, \mathrm{K}}=\left(\dot{m}_{K}-\dot{m}_{25}-\dot{m}_{26}\right)\left(h_{18}-h_{19}\right)
\end{aligned}
$$

The first law efficiency of the bottoming stage is expressed as follows:

$$
\eta_{n e t, K}^{\mathrm{I}}=1-\frac{\dot{Q}_{l, K}}{\dot{Q}_{h, K}}=\frac{\dot{W}_{n e t, K}}{\dot{Q}_{h, K}}
$$

The overall cycle efficiency, the first law efficiency, is the ratio of total output work to input heat. So, for the first law efficiency of the three-stage combined cycle power system we have:

$$
\eta_{\text {net }}^{\mathrm{I}}=1-\frac{\dot{Q}_{l, K}}{\dot{Q}_{\mathrm{h}, \mathrm{B}}}=\frac{\dot{W}_{\text {net }, \mathrm{B}}+\dot{W}_{\text {net }, \mathrm{R}}+\dot{W}_{\text {net }, \mathrm{K}}}{\dot{Q}_{\mathrm{h}, \mathrm{B}}}
$$

\section{Exergy analysis}

Exergy of a system is the "maximum shaft work that can be done by the composite of the system and a specified reference environment" [11]. In this study, exergy analysis is extensively utilized in order to better comprehend the true efficiencies by calculating the associated irreversibilities throughout the system. In addition, the true magnitude of losses, and their causes and locations are identified by examining the sites of exergy destruction to enhance the system efficiency. Exergy can be divided into four major components: physical, chemical, kinetic and potential. In this study, the chemical exergy is neglected and the system is considered to be at rest relative to the environment, (kinetic and potential terms are ignored), where the total system exergy became equivalent to the physical exergy of the system. The physical exergy is defined as the maximum theoretical useful work obtained as a system interacts with an equilibrium state [28-30] and it is expressed as:

$$
\dot{E} x_{\mathrm{ph}}=\dot{m}\left(\left(h-h_{0}\right)-T_{0}\left(s-s_{0}\right)\right)
$$

The exergy efficiency is the ratio of the available work to the reversible work:

$$
\begin{aligned}
\left(\dot{E} x_{w}\right)_{\mathrm{avl}} & =\dot{W}_{\mathrm{net}}=\dot{W}_{\mathrm{net}, \mathrm{B}}+\dot{W}_{\mathrm{net}, \mathrm{R}}+\dot{W}_{\text {net }, \mathrm{K}} \\
\left(\dot{E} x_{w}\right)_{\mathrm{rev}} & =\dot{Q}_{\mathrm{h}, \mathrm{B}}\left(1-\frac{T_{0}}{T_{4}}\right)-\dot{Q}_{l, K}\left(1-\frac{T_{0}}{T_{19}}\right) \\
\psi & =\frac{\left(\dot{E} x_{w}\right)_{\mathrm{avl}}}{\left(\dot{E} x_{w}\right)_{\mathrm{rev}}}
\end{aligned}
$$

The exergy of each flow in the plant is calculated and exergy destruction rates are determined for each component. The exergy destruction for each component of this energy system is shown in Table 1. 
A. Momeni et al.: Mechanics \& Industry 17, 502 (2016)

Table 1. Exergy destruction expression of three-stage combined cycle components.

\begin{tabular}{|c|c|}
\hline Gas turbine & $\dot{E} x_{D}=\dot{E} x_{4}-\dot{W}_{\text {turb }, \mathrm{B}}-\dot{E} x_{5}$ \\
\hline Steam turbine & $\dot{E} x_{D}=\dot{E} x_{13}-\dot{W}_{t u r b, R}-\dot{E} x_{14}-\dot{E} x_{15}-\dot{E} x_{16}$ \\
\hline Ammonia-water turbine & $\dot{E} x_{D}=\dot{E} x_{17}-\dot{W}_{t u r b, K}-\dot{E} x_{25}-\dot{E} x_{26}-\dot{E} x_{18}$ \\
\hline Condenser & $\dot{E} x_{D}=\dot{E} x_{18}-\dot{E} x_{19}$ \\
\hline Combustion chamber & $\dot{E} x_{D}=\dot{E} x_{4}-\dot{E} x_{3}$ \\
\hline Gas compressor & $\dot{E} x_{D}=\dot{W}_{\text {comp }, \mathrm{B}}+\dot{E} x_{1}-\dot{E} x_{2}$ \\
\hline Steam pumps & $\dot{E} x_{D}=\dot{W}_{\mathrm{pumps}, \mathrm{R}}+\dot{E} x_{7}-\dot{E} x_{8}+\dot{E} x_{9}-\dot{E} x_{10}+\dot{E} x_{11}-\dot{E} x_{12}$ \\
\hline Ammonia-water pumps & $\dot{E} x_{D}=\dot{W}_{\mathrm{pumps}, \mathrm{K}}+\dot{E} x_{19}-\dot{E} x_{20}+\dot{E} x_{21}-\dot{E} x_{22}+\dot{E} x_{23}-\dot{E} x_{24}$ \\
\hline Recuperator & $\dot{E} x_{D}=\dot{E} x_{5}-\dot{E} x_{3}+\dot{E} x_{2}-\dot{E} x_{6}$ \\
\hline Heat exchanger 1 & $\dot{E} x_{D}=\dot{E} x_{6}-\dot{E} x_{1}+\dot{E} x_{12}-\dot{E} x_{13}$ \\
\hline Heat exchanger 2 & $\dot{E} x_{D}=\dot{E} x_{16}-\dot{E} x_{7}+\dot{E} x_{24}-\dot{E} x_{17}$ \\
\hline Steam mixer 1 & $\dot{E} x_{D}=\dot{E} x_{8}+\dot{E} x_{15}-\dot{E} x_{9}$ \\
\hline Steam mixer 2 & $\dot{E} x_{D}=\dot{E} x_{10}+\dot{E} x_{14}-\dot{E} x_{11}$ \\
\hline Ammonia-water mixer 1 & $\dot{E} x_{D}=\dot{E} x_{20}+\dot{E} x_{26}-\dot{E} x_{21}$ \\
\hline Ammonia-water mixer 2 & $\dot{E} x_{D}=\dot{E} x_{22}+\dot{E} x_{25}-\dot{E} x_{23}$ \\
\hline
\end{tabular}

\section{Economic analysis}

In order to conduct the economic analysis, the purchase cost function of each component in the system is required as a function of design parameters that can be used in the optimization study.

\subsection{Purchase cost functions}

Purchase cost equations of the components in the three-stage combined cycle power systems can be expressed as follows [31,32]:

$$
\begin{aligned}
Z_{\text {Combustion Chamber }}= & 289.8 \dot{m}_{B}\left(1+\mathrm{e}^{\left(0.015\left(T_{4}-1540\right)\right)}\right) \\
Z_{\text {Gas Turbine }}= & 301.5 \dot{m}_{B}\left(\frac{1}{0.94-\eta_{\text {turb }}}\right) \\
& \ln R_{p}\left(1+\mathrm{e}^{\left(0.025\left(T_{4}-1540\right)\right)}\right) \\
Z_{\text {Air Compressor }}= & 44.7 \dot{m}_{B}\left(\frac{1}{0.95-\eta_{\text {comp }}}\right) R_{P} \ln R_{P} \\
Z_{\text {recuperator }}= & 43269.9 A_{\text {recup }}^{0.6019} \\
Z_{\text {Heat Exchanger } 1}= & 10719.1 A_{\mathrm{HE} 1}^{0.6942} \\
Z_{\text {Steam Turbine }}= & 3880.5 \dot{W}_{\text {turb }}^{0.7}\left(1+\left(\frac{0.05}{1-\eta_{\text {turb }}}\right)^{3}\right) \\
& \times\left(1+\frac{T_{13}-800}{10.42}\right) \\
Z_{\text {Heat Exchanger2 }}= & 10719.1 A_{\mathrm{HE} 2}^{0.6942} \\
Z_{\text {Pumps }}= & 705.5 \dot{W}_{\text {pumps }}^{0.7}\left(1+\frac{2}{1-\eta_{\text {pump }}}\right)
\end{aligned}
$$

$$
\begin{aligned}
Z_{\text {Kalina Turbine }}= & 3880.5 \dot{W}_{\text {turb }}^{0.7}\left(1+\left(\frac{0.05}{1-\eta_{\text {turb }}}\right)^{3}\right) \\
& \times\left(1+\frac{T_{17}-600}{10.42}\right) \\
Z_{\text {Condenser }}= & 94693.3 A_{\text {cond }}^{0.4652}
\end{aligned}
$$

And finally the total purchase cost of the system is calculated as:

$$
\begin{aligned}
Z_{\text {tot }} & =\sum\left(Z_{\text {Combustion Chamber }}+Z_{\text {Gas Turbine }}\right. \\
& +Z_{\text {Air Compressor }}+Z_{\text {recuperator }}+Z_{\text {Heat Exchanger } 1} \\
& +Z_{\text {Steam Turbine }}+Z_{\text {Heat Exchanger2 }}+Z_{\text {Pumps }} \\
& \left.+Z_{\text {Kalina Turbine }}+Z_{\text {Condenser }}\right)
\end{aligned}
$$

Estimation of heat transfer area of the cycle components is necessary to perform economic analysis. Heat transfer rate of all components which exchanged heat into or out of the cycle, including recuperator, heat exchangers and condenser, can be expressed by overall heat transfer coefficient and mean logarithm temperature:

$$
\dot{Q}=U A \Delta T_{m}
$$

Overall heat transfer coefficient and mean logarithm temperature of the cycle components are listed in Table 2 [33].

\subsection{Capital recovery factor (CRF)}

A capital recovery factor converts a present value into a stream of equal and annual payments over a given length of time at a given interest rate $(i)$ [21] and it is defined as:

$$
C R F=\frac{i \times(1+i)^{n}}{(1+i)^{n}-1}
$$

Here, $i$ denotes the interest rate and $n$ the total operating period of the system in years. 
A. Momeni et al.: Mechanics \& Industry 17, 502 (2016)

Table 2. Overall heat transfer coefficients and mean logarithm temperature.

\begin{tabular}{ccc}
\hline component & $\begin{array}{c}\text { Overall heat transfer } \\
\text { coefficient } U\left(\mathrm{~W} \cdot \mathrm{m}^{-2} . \mathrm{C}\right)\end{array}$ & $\begin{array}{c}\text { Mean logarithm } \\
\text { temperature } \Delta T_{m}(\mathrm{~K})\end{array}$ \\
\hline Recuperator & 10 & $\left(\left(T_{6}-T_{2}\right)-\left(T_{5}-T_{3}\right)\right) / \ln \left(\frac{T_{6}-T_{2}}{T_{5}-T_{3}}\right)$ \\
Heat exchanger 1 & 25 & $\left(\left(T_{1}-T_{12}\right)-\left(T_{6}-T_{13}\right)\right) / \ln \left(\frac{T_{1}-T_{12}}{T_{6}-T_{13}}\right)$ \\
Heat exchanger 2 & 850 & $\left(\left(T_{7}-T_{24}\right)-\left(T_{16}-T_{17}\right)\right) / \ln \left(\frac{T_{7}-T_{24}}{T_{16}-T_{17}}\right)$ \\
Condenser & 850 & $\left(\left(T_{19}-T_{0}\right)-\left(T_{18}-T_{\text {out }}\right)\right) / \ln \left(\frac{T_{19}-T_{0}}{T_{18}-T_{\text {out }}}\right)$ \\
\hline
\end{tabular}

\subsection{Cost rate}

Since each device in a system is expected to be working in a specific time frame, the cost rate of each device is a good indicator to calculate the cost rate in $\$ / \mathrm{s}$ determined as:

$$
\dot{Z}=\frac{Z_{J} \times C R F \times \varphi}{N \times 3600}
$$

where $Z_{J}$ is the purchase cost of the $J$ th component, and $C R F$ is the capital recovery factor. Also, $N$ is the annual number of operation hours for the unit, and $\varphi$ is the maintenance factor, which is often 1.06 [34].

\section{Multi-objective optimization}

Based on evolutionary algorithm, a multi-objective optimization method is applied to the three-stage combined cycle power system. In this section, objective functions, design parameters and constraints, and overall optimization are described.

\subsection{Definition of objectives}

Two objective functions are considered here for multiobjective optimization: exergy efficiency (to be maximized) and total product cost rate (to be minimized). Consequently, the objective functions in this analysis can be expressed as follows:

$$
\begin{aligned}
\psi & =\frac{\left(\dot{E} x_{w}\right)_{\mathrm{avl}}}{\left(\dot{E} x_{w}\right)_{\text {rev }}} \\
\dot{Z}_{\text {tot }} & =\sum\left(\dot{Z}_{\text {Combustion Chamber }}+\dot{Z}_{\text {Gas Turbine }}\right. \\
& +\dot{Z}_{\text {Air Compressor }}+\dot{Z}_{\text {recuperator }}+\dot{Z}_{\text {Heat Exchanger } 1} \\
& +\dot{Z}_{\text {Steam Turbine }}+\dot{Z}_{\text {Heat Exchanger } 2}+\dot{Z}_{\text {Pumps }} \\
& \left.+\dot{Z}_{\text {Kalina Turbine }}+\dot{Z}_{\text {Condenser }}\right)
\end{aligned}
$$

\subsection{Decision variables}

The following decision variables (design parameters) are selected for this study: gas turbine inlet temperature $\left(T_{4}\right)$, gas condenser outlet temperature $\left(T_{1}\right)$, steam condenser outlet temperature $\left(T_{7}\right)$, Kalina condenser outlet temperature $\left(T_{19}\right)$, Kalina cycle condenser pressure $\left(P_{19}\right)$,
Table 3. Optimization constraints.

\begin{tabular}{cc}
\hline constraint & Reason \\
\hline$T_{4} \leq 1650 \mathrm{~K}$ & Material temperature limit \\
$P_{12} \leq 16 \mathrm{MPa}$ & Commercial availability \\
$P_{24} \leq 16 \mathrm{MPa}$ & Commercial availability \\
$\eta_{\text {turb }} \leq 0.85 \%$ & Commercial availability \\
$\eta_{\text {comp }} \leq 0.90 \%$ & Commercial availability \\
$\eta_{\text {pump }} \leq 0.90 \%$ & Commercial availability \\
\hline
\end{tabular}

first bottoming pressure of the Kalina cycle $\left(P_{20}\right)$, second middle pressure of Kalina cycle $\left(P_{22}\right)$ and evaporator pressure of the Kalina cycle $\left(P_{24}\right)$. In the optimization procedure, decision variables vary in reasonable ranges. These constraints are listed in Table 3.

\subsection{Evolutionary algorithm: genetic algorithm}

Today, many search techniques are being utilized in order to deal with multi-objective optimization problems. Generic algorithm, simulated annealing, tabu and scatter search, ant system, particle swarm and fuzzy programing are the most commonly used among them. Since no single technique is able to provide the optimum results for all problems, the best method should be selected with respect to the system at hand. In this study, generic algorithm is used, mainly since it does not require initial conditions, works with multiple design variables, finds global optima, utilizes populations and uses objective function formation.

Generic algorithms apply an iterative and stochastic search strategy to reach towards an optimal solution and have been starting to be used for wide range of applications within both academia and industry. Based on the inspired evolutionary process, the strong species have greater opportunity to pass their genes to future generations and thus the good genes are expected to appear more frequently in the population, making them the dominant population over time whereas the weak genes appears less frequently and these species face extinction.

In the conducted analysis, a solution vector (chromosome) consists of discrete units (genes) that control a number of chromosome features which corresponds to a unique solution in the solution space. Moreover, the collection of these chromosomes (population) is initialized randomly at first and includes solutions with increasing fitness as the search evolves until converging to a single solution. Furthermore, operators called crossover and 


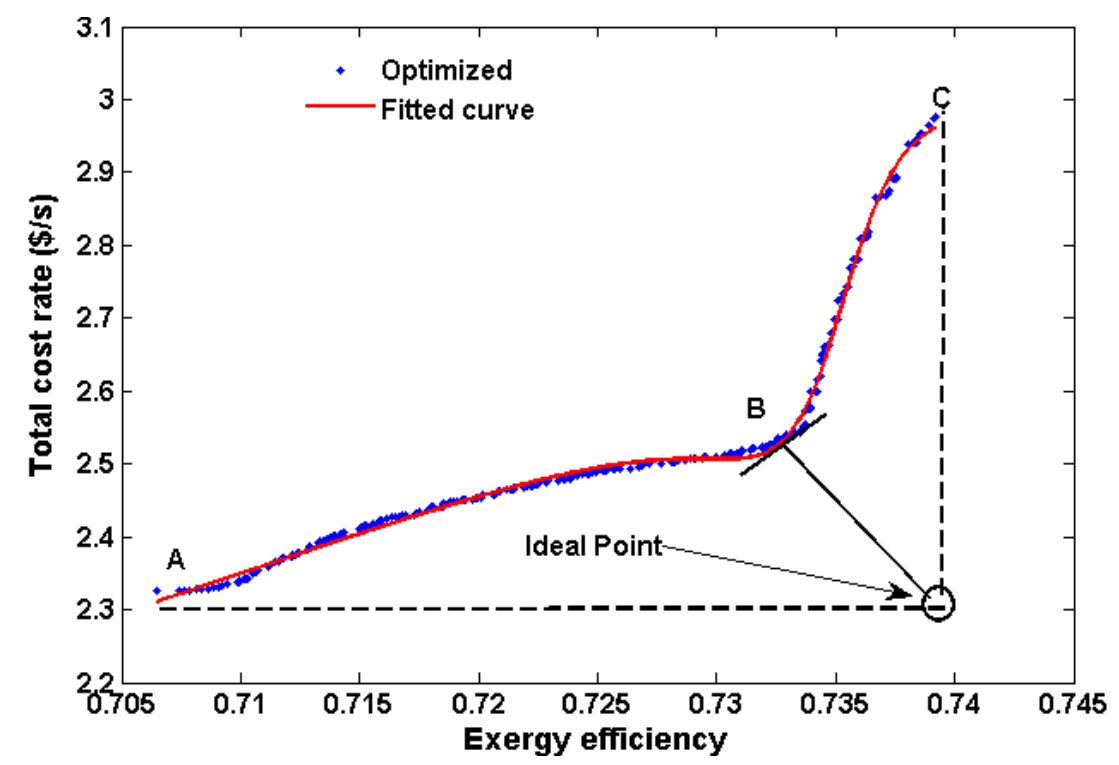

Fig. 2. Pareto Frontier, Best trade off values for the objective functions.

mutation are used to generate new solutions from existing ones $[35,36]$.

Generic algorithms have considerably advantages and therefore they are widely used for various multi-objective optimization applications since any type of constraints can be implemented without much difficulty. Moreover, they can also find multiple near-optimal points in the optimization space, which allows the selection of the most valid solution for the specific optimization problem.

\section{Results and discussion}

The results of the thermodynamic modeling as well as exergy and economic analyses are presented along with sensitivity analyses with respect to varying several design parameters on cycle performance. The genetic algorithm optimization is performed for 250 generations, using a search population size of $M=100$ individuals, a crossover probability of $p_{c}=0.9$, a gene mutation probability of $p_{m}=0.035$ and a controlled elitism value $c=0.55$. The results of the optimization are given and described below.

\subsection{Optimization results}

Figure 2 shows the Pareto frontier solution for this combined system with objective functions indicated in Equations (58) and (59) in multi-objective optimization. It is shown in this figure that the total cost rate of products increases moderately as the total exergy efficiency of the cycle increases to about $71 \%$. Increasing the total exergy efficiency from $71 \%$ to $74 \%$ increases the cost rate of product significantly. The results of optimum exergy efficiency and total cost rate for all points evaluated over 300 generations are shown in Figure 2. As shown in Figure 2, the maximum exergy efficiency exists at design point $C(74 \%)$, while the total cost rate of products is the greatest at this point $(2.97 \$ / \mathrm{s})$.

On the other hand, the minimum value for the total product cost rate occurs at design point $A$ which is about $2.33 \$ / \mathrm{s}$. It can be seen that design point $\mathrm{A}$ only pays attention to its own criterion (total cost rate) without taking any other criteria (exergy efficiency) into consideration, whereas the opposite is true for design point $\mathrm{C}$. Since all the points on the Pareto optimum frontier are potentially an optimum solution for the analysis, a hypothetical ideal point is selected to determine a desirable final solution. In this selected point, optimum values exist for all objectives independent of each other and stay below the Pareto optimum frontier as shown in Figure 2. Although it is not feasible to achieve this point, it becomes useful by enabling the decision makers to select the point on the Pareto optimum frontier that has the closest distance to this ideal point as the desirable final solution.

Nevertheless, in this case, the Pareto optimum frontier exhibits weak equilibrium by having a small change in one objective (from varying the operating parameters) to cause a large variation in the other one. Thus, the ideal point cannot be utilized for decision-making in this problem. In selection of the final optimum point, it is desired to achieve a better magnitude for each objective function than its initial value for the base case problem noting that in multi-objective optimization and the Pareto solution, each point can be utilized as the optimized point. Therefore, the selection of the optimum solution (through the corresponding point on the frontier) depends on the corresponding weighting factors, preferences and criteria of the decision maker.

As shown in Figure 2, the optimized values for exergy efficiency on the Pareto frontier range between $70 \%$ and $74 \%$. In order to provide a good relation between exergy efficiency and total cost rate of the system, a curve is 


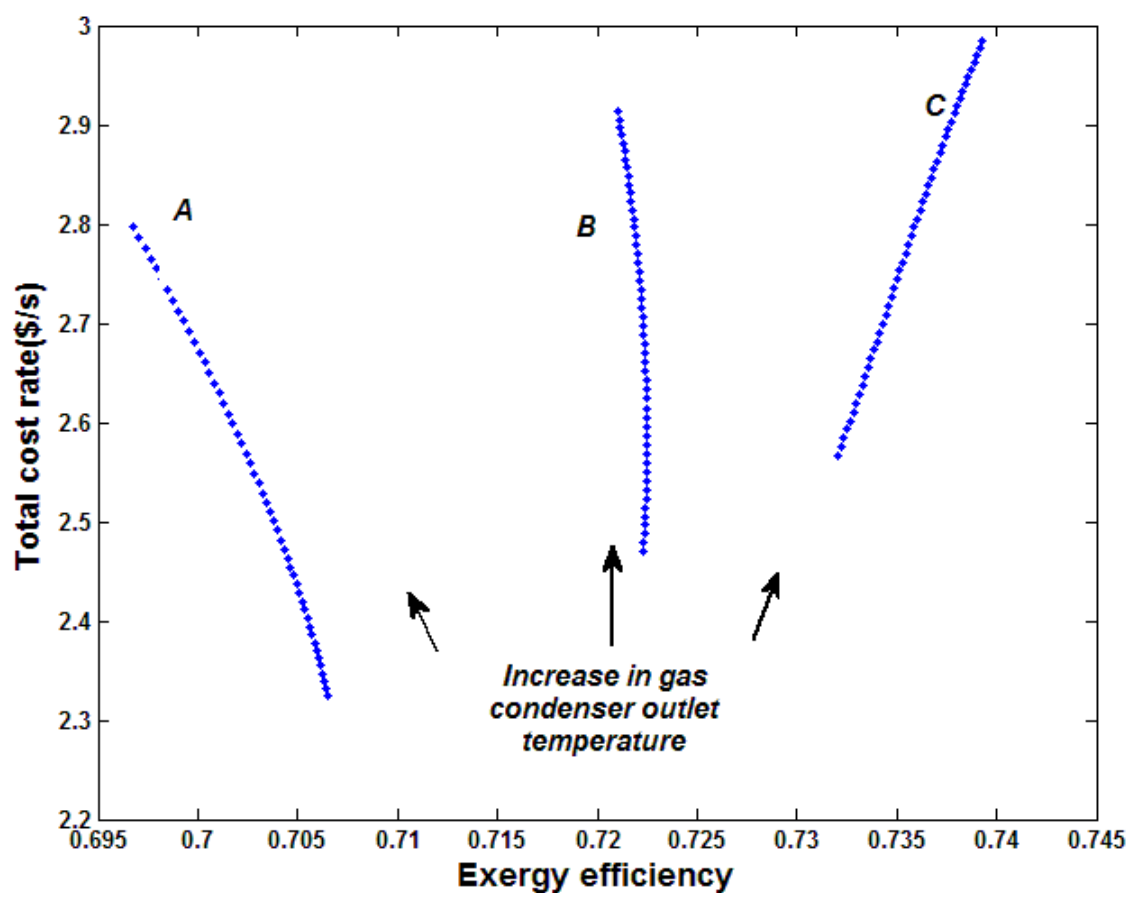

Fig. 3. Effects of gas condenser outlet temperature on both objective functions.

fitted on the optimized points obtained from the evolutionary algorithm. This fitted curve is shown in Figure 2 and the expression for this fitted curve follows:

$$
\dot{Z}_{\text {tot }}=\frac{5.98 \psi^{3}-5.13 \psi^{2}-2.1 \psi+1.98}{\psi^{5}-11.59 \psi^{4}+13.14 \psi^{3}-7.55 \psi^{2}-15.46 \psi-5.22}
$$

This is allowable when the efficiency varies between $70 \%$ and $75 \%$. To study the variation of thermodynamic characteristics, three different points $(A$ to $C$ ) on the Pareto frontier are considered.

\subsection{Sensitivity analysis}

In order to have a better understanding of the multiobjective optimization, a comprehensive sensitivity analysis is performed. The effects of each of the design parameters for points $A-C$ on both objective functions are investigated. It is important to know that a change in any parameter affects the system performance and results in a change in all the thermodynamic properties of all the streams in Figure 1. Therefore, a comprehensive conclusion would be really difficult to see the exact effect of a variation of the selected parameters. However, the consequence of different effects on the performance assessment is reported here. The effects of the lowest temperature of Brayton cycle (topping stage), $T_{1}$, on both objective functions of the system are shown in Figure 3. It is observed from this figure that an increase in this temperature results in an increase in the total cost rate of the system which is mainly due to an increase in purchase cost of turbine and heat exchangers. On the other hand, an increase in this temperature has two major effects on the system performance, first this increase results in a decrease in logarithm mean temperature of heat exchanger between top and middle stages and also an increase in turbine inlet temperature of steam and Kalina turbines according to Equations (49) and (52), respectively. Thus, variation of the system total cost rate with $T_{1}$ is meaningful. Any enhancement of this parameter increases the total cost rate because cost rates of turbines and heat exchangers are strong function of this parameter. It is also observed from Figure 3 that at lower values of this temperature (e.g. $570 \mathrm{~K}$ ) an increase in this temperature decreases the exergy efficiency while at the higher values of this temperature (e.g. $590 \mathrm{~K}$ ) the exergy efficiency of the system increases by enhancement of the lowest temperature of the Brayton cycle. Variation of the exergy efficiency with this temperature is explained by exergy destruction rate of heat exchangers listed in Table 1. Variation of this temperature in its allowable range leads to first decrease in the outlet exergy of heat exchanger 1 followed by an increase in outlet exergy of heat exchanger 1 . Figure 4 shows the effect of gas turbine inlet temperature $\left(T_{4}\right)$ on both objective functions. It is observed that an increase in this parameter results in a decrease in exergy efficiency while this increase leads to an increase in total cost rate of the system. An increase in $T_{4}$ results in an increase in total cost rate of the system due to enhancement of turbine cost rate. Also heat exchangers exergy destruction rate of this combined cycle increases by increasing this parameter according to Equations (44) and (45) and Table 1, respectively. To discuss about the exergy efficiency trend, when the gas turbine inlet temperature increase several effects should be fully considered and addressed. Available work and reversible work are increased by an increase in $T_{4}$, Equations (41) and (42), respectively. Consequently, 
A. Momeni et al.: Mechanics \& Industry 17, 502 (2016)

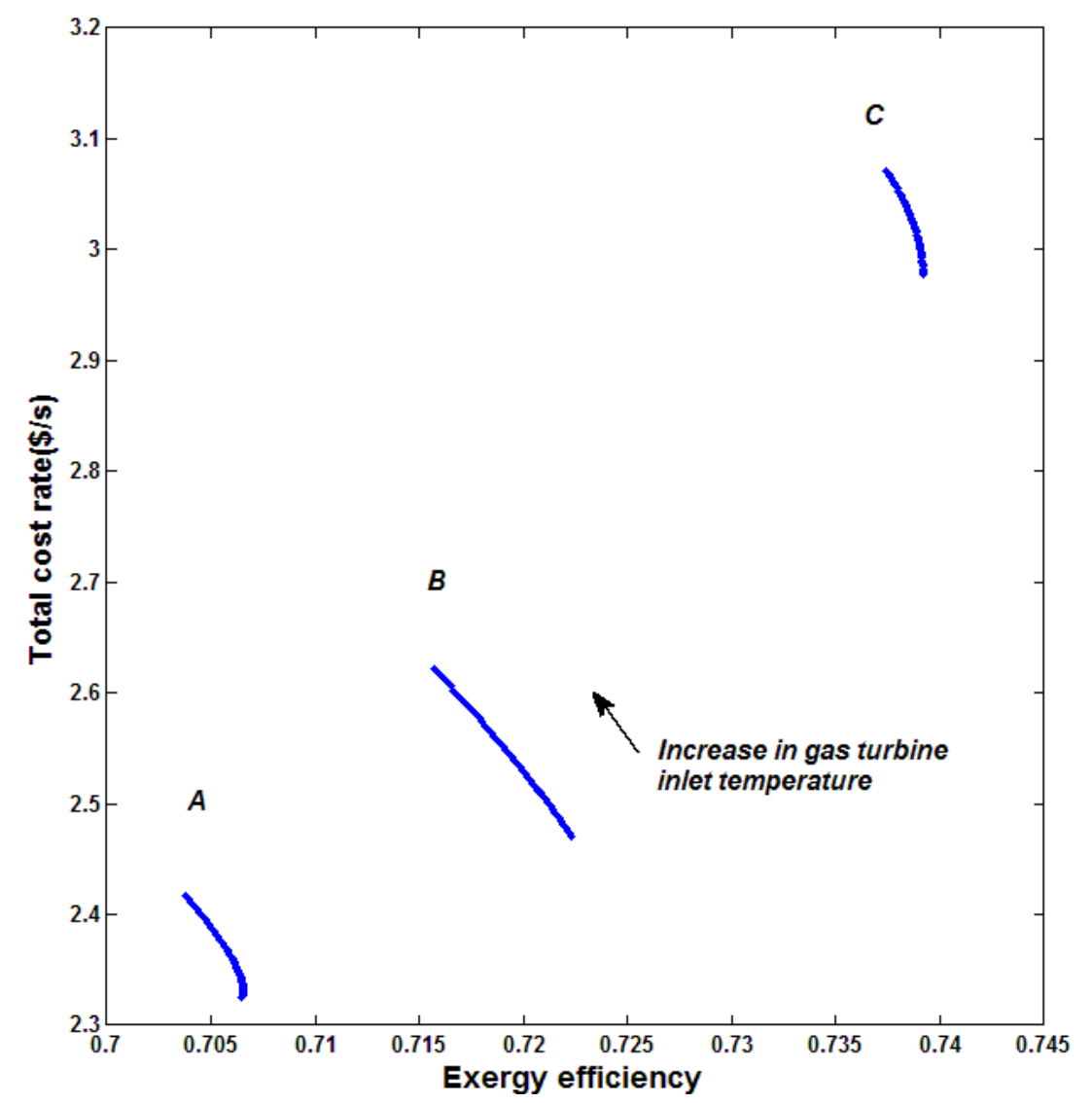

Fig. 4. Effects of gas turbine inlet air temperature on both objective functions.

growth rate of these works to each other determines that exergy efficiency is increased or decreased where in this temperature range leads to decrease in exergy efficiency, (Eq. (43)). Therefore, the higher value of this parameter is not favourable. The effects of the steam cycle lowest temperature (e.g., the middle stage) on both objective functions are investigated in Figure 5. The higher values of this parameter are not favourable because the purchase cost of Kalina turbine and exergy destruction rate of heat exchanger 2 increase, (Eq. (52) and Tab. 1). On the other hand, Kalina turbine inlet temperature and inlet exergy of heat exchanger between the middle and bottom stages increase due to an increase in this temperature. Increasing this temperature leads to an increase in the inlet temperature of the Kalina turbine, so exergy destruction rate of the Kalina turbine increases and consequently overall exergy efficiency decreases, Table 1 and Equation (43), respectively. Figure 6 shows the variation of both objective functions when the Kalina condenser outlet temperature varies within allowable range. It is shown that an increase in this parameter leads to an increase in system exergy efficiency. However, it results in a decrease in the total cost rate of the system which is due to an increase in logarithm mean temperature of condenser of the Kalina cycle, (Tab. 2). An increase in this logarithmic temperature results in decrease in condenser area, (Eq. (55)). Since the condenser cost is a function of its area the lower the condenser area leads to the lower purchase cost, (Eq. (53)). In addition, exergy efficiency increases due to the fact that exergy destruction rate of heat exchangers decreases, according to Table 1. This is because of the fact that the rate of increase in outlet exergy flows to heat exchanger numbers 1 and 2 is much higher than the inlet exergy flows to these heat exchanges. Therefore, the exergy destruction rate of these heat exchangers decreases when the temperature increases according to the information provided in Table 1 and the exergy efficiency of the system increases consequently according to Equation (43).

As it was already explained, three-stage combined power systems with ammonia-water mixture at bottoming cycle are a novel power generation approach. Therefore, the effects of four pressure levels of bottoming cycle on both objective functions are shown in Figures 7-10. Figure 7 illustrates the variation of both objective functions with respect to the Kalina cycle condenser pressure. It is clearly observed from this figure that an increase in condenser pressure of the Kalina cycle within its allowable range leads to a decrease in exergy efficiency. This can be explained by analyzing the exergy destruction rate of heat exchangers. According to Table 1, enhancement of inlet exergy leads to more exergy destruction and inlet exergy in this case is increased by increasing this pressure because enthalpy of ammonia-water mixture increases. However, total cost rate decreases first followed by an increase in the total cost rate. Variation of total cost rate of the system is explained by the Kalina pumps and its turbine 
A. Momeni et al.: Mechanics \& Industry 17, 502 (2016)

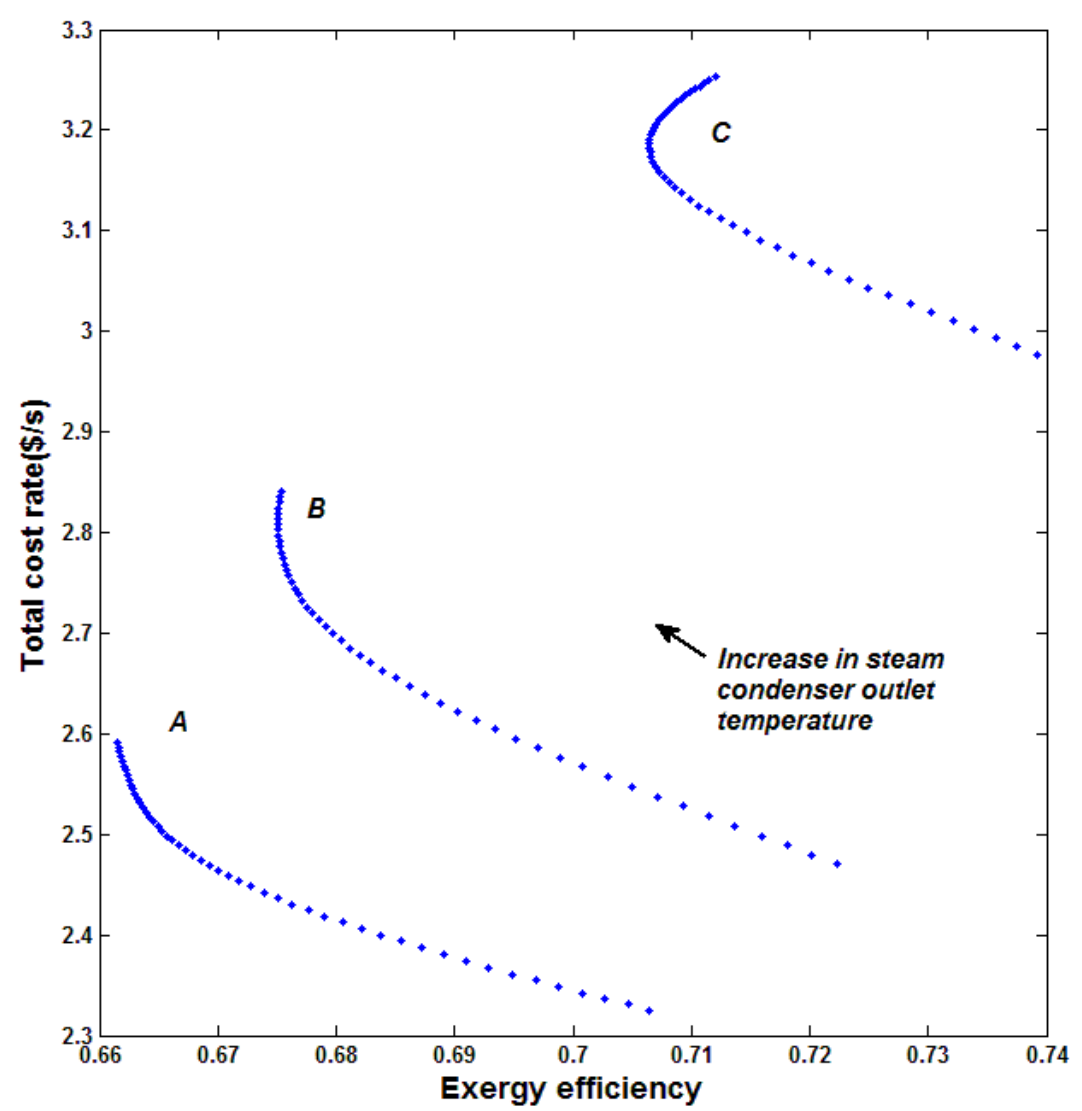

Fig. 5. Effects of steam condenser outlet temperature on both objective functions.

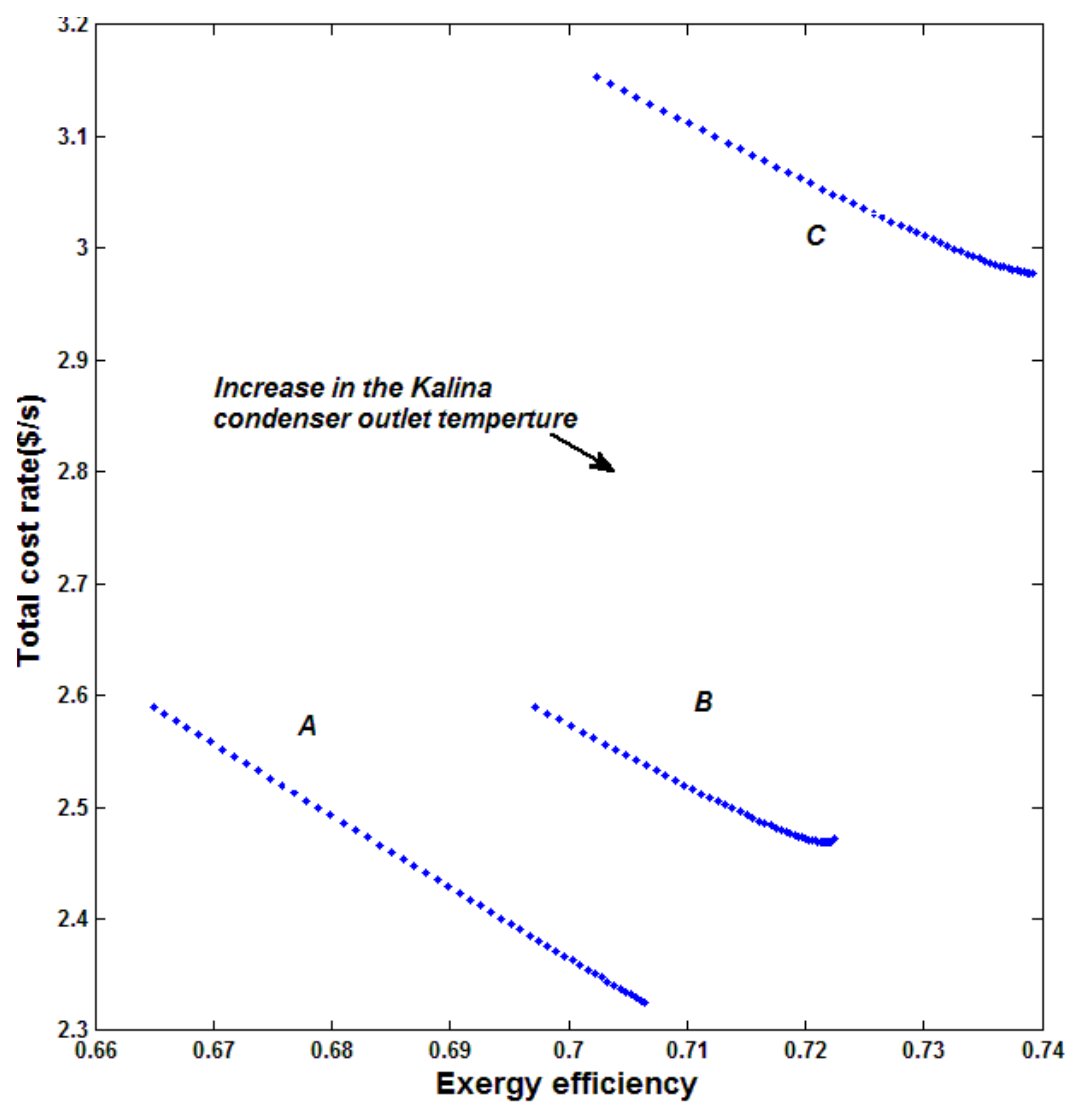

Fig. 6. Effects of the Kalina condenser outlet temperature on both objective functions. 
A. Momeni et al.: Mechanics \& Industry 17, 502 (2016)

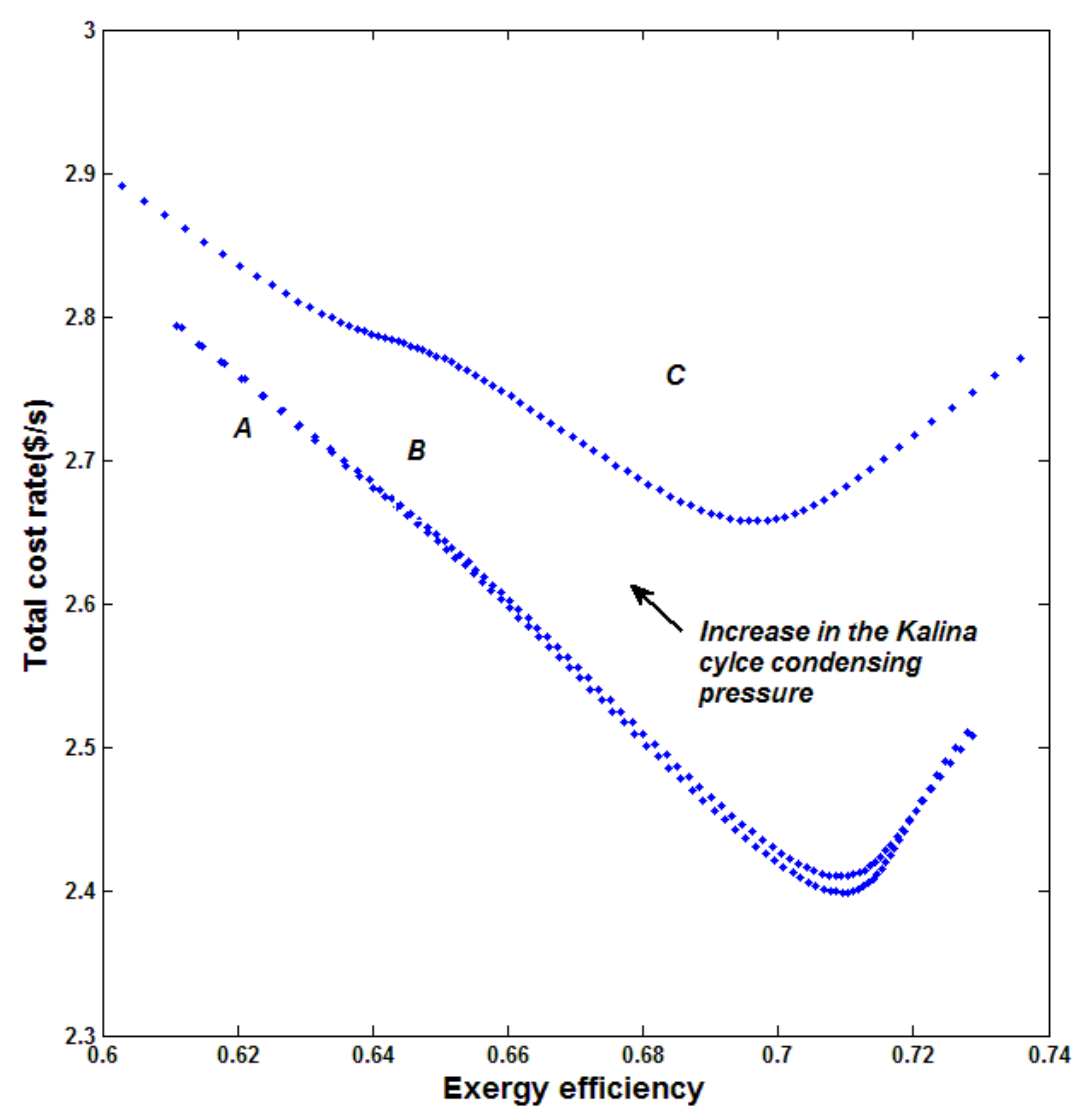

Fig. 7. Effects of the Kalina cycle condensing pressure on both objective functions.

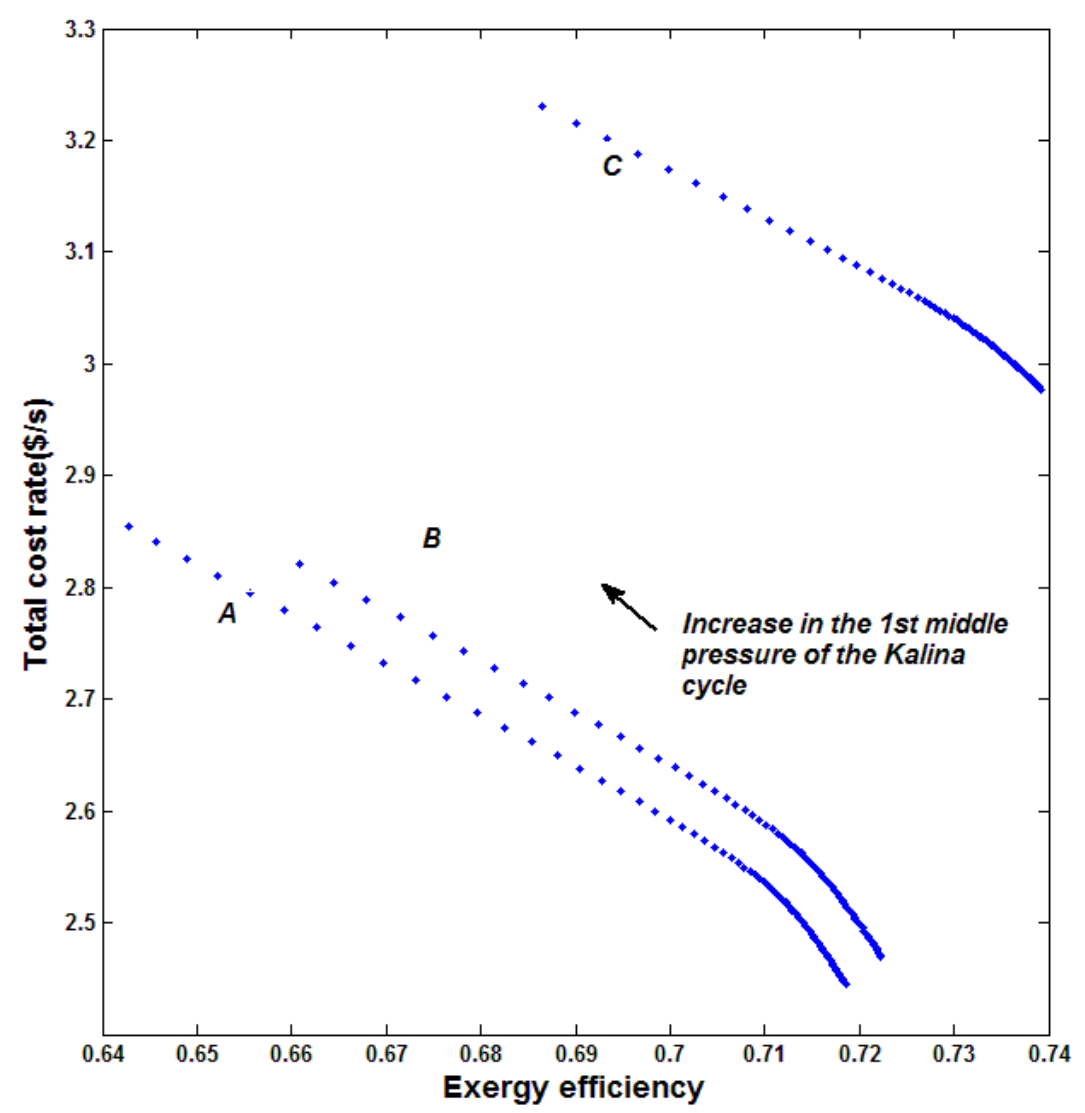

Fig. 8. Effects of the first middle pressure of the Kalina cycle on both objective functions. 
A. Momeni et al.: Mechanics \& Industry 17, 502 (2016)

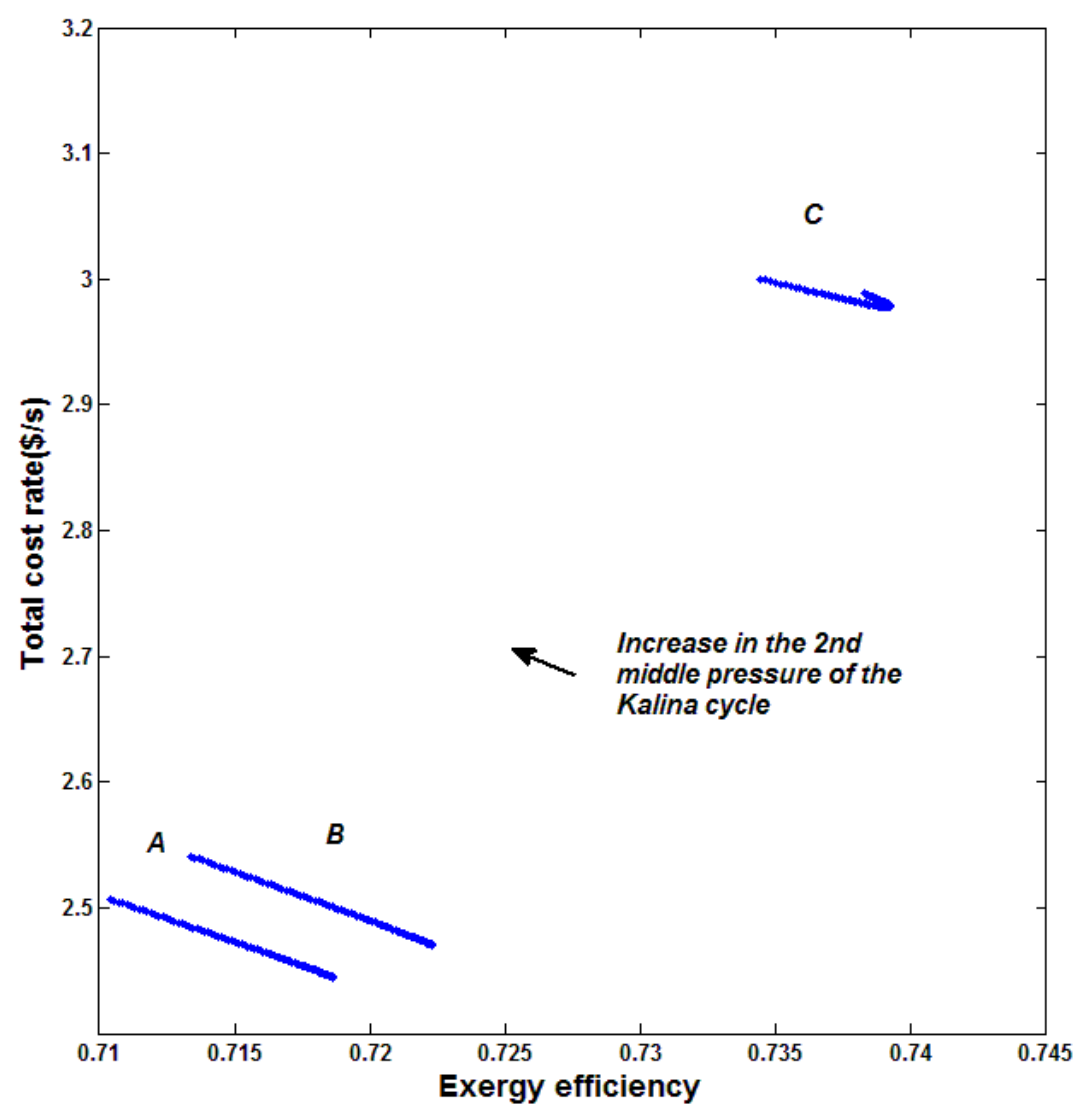

Fig. 9. Effects of the second middle pressure of the Kalina cycle on both objective functions.

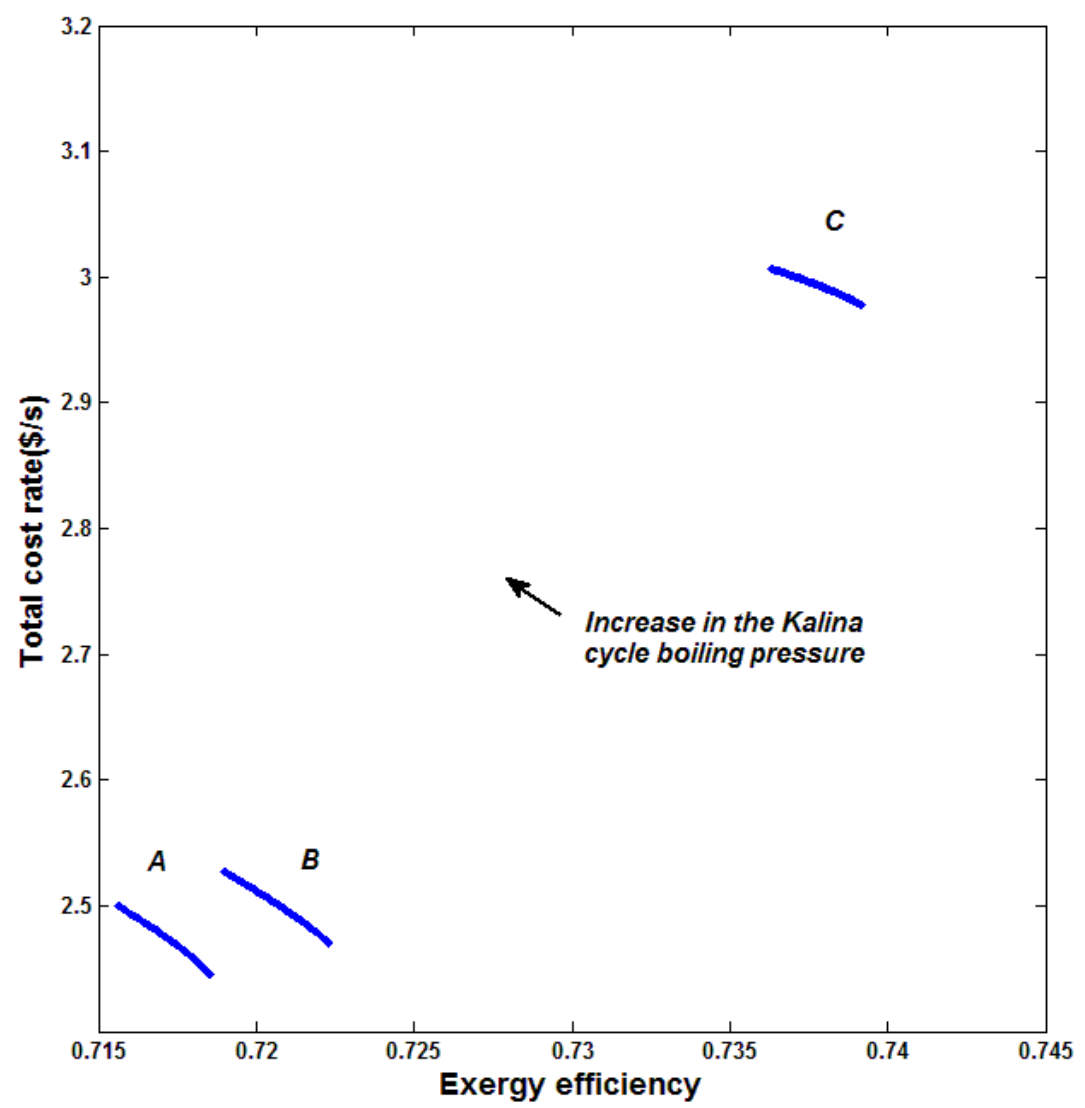

Fig. 10. Effects of the Kalina evaporator pressure on both objective functions. 
cost rate, Equations (51) and (52), respectively. Variation of total cost rate with the Kalina condensing pressure is reasonable by concentrating on its pumps and turbine power changes, Equations (33) and (34), respectively. At first, by increasing this pressure enthalpy differences between inlets and outlets of the Kalina pumps decrease and this leads to decrease in pumps and overall cost rate, (Eq. (54)), however, this pressure enhancement leads to increase in inlet enthalpy of Kalina turbine and based in Equations (34) and (54) exergy efficiency increases. An increase in this pressure leads to enhancement of heat exchangers exergy destruction, Kalina turbine and mixers exergy destruction, (Tab. 1). The main component which is affected by this pressure enhancement is the Kalina turbine exergy destruction. This parameter is direct function of inlet exergy to the Kalina turbine.

As it is clear from Figure 8, the first middle pressure of the Kalina cycle has significant effects on both objective functions. Exergy destruction of heat exchangers increases because an increase in this middle pressure increases the inlet exergy of the heat exchangers. On the other hand, increasing this pressure leads to an increase in inlet enthalpy of heat exchangers and finally exergy flow of heat exchangers inlets increases, Equation (40). It can be obtained from Table 1 that exergy efficiency decreases because of enhancement of heat exchangers exergy destruction, (Eq. (43)). This pressure is directly in contact with power generation of the Kalina turbine, (Eq. (34)). By increasing this pressure enthalpy differences between inlets and outlets of the Kalina turbine increase and its power generation and cost rate are also increased and consequently total cost rate is increased, Equations (34), (52) and (54), respectively. Similar consequences for the second middle pressure of the Kalina cycle can be concluded. Increasing this pressure increases enthalpy differences between inlets and outlets of the Kalina turbine and power generation, (Eq. (34)). So the Kalina turbine cost rate and consequently total cost rate are increased, Equations (52) and (54), respectively. Increasing this pressure leads to an increase in inlet enthalpy of heat exchangers and exergy flow of heat exchangers inlets increases, (Eq. (40)). Exergy efficiency decreases because of enhancement of heat exchangers exergy destruction, (Eq. (43) and Tab. 1).

Effects of the Kalina evaporator pressure on total cost rate and exergy efficiency are shown in Figure 10. Increasing the evaporator pressure within its allowable range, increases the exergy flow differences between inlets and outlets of the Kalina cycle heat exchanger (heat exchanger 2 ). Inlet exergy flow of the Kalina turbine is also increased by increasing the evaporator pressure. Based on the exergy destruction of components, Table 1, by increasing evaporator pressure exergy efficiency decreases, (Eq. (43). The cost rate of the Kalina turbine and its pumps increases by any enhancement of the evaporator pressure because enthalpy differences between outlets and inlets of pumps and turbine increase and it leads to increase in power consumption and power generation of pumps and turbine, Equations (33) and (34), respectively. By increasing pumps and turbine work, their cost rates increase and consequently the total cost rate of the system increases according to Equations (51), (52) and (54), respectively.

\section{Conclusions}

The comprehensive thermo-economic and multiobjective optimization of a three-stage combined cycle power system using ammonia-water mixture has provided advantageous insights. Optimization procedure of a threestage combined cycle requires the utilization of multiobjective optimization to be practical and comprehensive. Two objective functions, namely total cost rate and exergy efficiency, are used where they are minimized and maximized respectively. The Pareto frontier for each objective function along with the equation derived from the corresponding points enables the users to better understand the trade-offs among the studied factors and assists them with making better decisions based on their selected criteria. We may extract some concluding remarks as follows:

- The comprehensive model of the three-stage combined cycle power systems was developed by concentrating on sensitivity analysis of the design parameters.

- Exergy efficiency and total product cost rate as two objectives are optimized simultaneously by applying multi-objective optimization technique.

- Maximum exergy efficiency is $74 \%$, while the total cost rate of products is $2.97 \$ / \mathrm{s}$.

- Minimum total cost rate of products is $2.33 \$ / \mathrm{s}$, while the exergy efficiency is $71 \%$.

- At the ideal point of multi-objective optimization, exergy efficiency is $74 \%$ and total cost rate is $2.3 \$ / \mathrm{s}$. However, this point is not practically feasible to achieve.

- The closest distance to the ideal point is selected as the desirable final solution with exergy efficiency of $73.4 \%$ and total cost rate of $2.56 \$ / \mathrm{s}$.

\section{References}

[1] C. Zamfirescu, I. Dincer, Thermodynamic analysis of a novel ammonia-water trilateral Rankine cycle, Thermochim. Acta 447 (2008) 7-15

[2] A. Kalina, Combined cycle system with novel bottoming cycle, J. Eng. Gas Turbines Power 106 (1984) 737-742

[3] M. Jonsson, J. Yan, Ammonia-water bottoming cycles: a comparison between gas engines and gas diesel engines as prime movers, Energy 26 (2001) 31-44

[4] T. Srinivas, A. Gupta, B. Reddy, Performance Simulation of Combined Cycle with Bottoming cycle, Cogeneration and Distributed generation Journal 26 (2008) 6-21

[5] S. Ogriseck, Integration of Kalina cycle in a combined heat and power plant, a case study, Appl. Thermal Eng. 29 (2009) 2843-2848

[6] W.R. Wagar, C. Zamfirescu, I. Dincer, Thermodynamic performance assessment of an ammonia-water Rankine cycle for power and heat production, Energy Convers. Manag. 51 (2010) 2501-2509 
[7] X. Shi, D. Che, A combined power cycle utilizing lowtemperature waste heat and LNG cold energy, Energy Convers. Manag. 50 (2009) 567-575

[8] F. Sun, Y. Ikegami, B. Jia, A study on Kalina solar system with auxiliary superheater, Renew. Energy 41 (2012) 210-219

[9] P.A. Lolos, E.D. Rogdakis, A Kalina Power cycle driven by renewable energy sources, Energy 34 (2009) 457-464

[10] C. Dejfors, E. Thorin, G. Svedberg, Ammonia-water power cycle for direct fired cogeneration applications, Energy Convers. Manag. 39 (1998) 1675-1681

[11] M. Rosen, I. Dincer, M. Kanoglu, Role of exergy in increasing efficiency and sustainability and reducing environmental impact, Energy Policy 36 (2008) 128-137

[12] R. Padilla, G. Demirkaya, D. Goswami, E. Stefanakos, R. Rahman, Analysis of power and cooling cogeneration using ammonia-water mixture, Energy 35 (2010) 46494657

[13] P. Ahmadi, I. Dincer, M. Rosen, Exergo-environmental analysis of an integrated organic Rankine cycle for trigeneration, Energy Convers. Manag. 64 (2012) 447-453

[14] M. Liu, N. Zhang, Proposal and analysis of a novel ammonia-water cycle for power and refrigeration cogeneration, Energy 32 (2007) 961-970

[15] A. Vidal, R. Best, R. Rivero, J. Cervantes, Analysis of a combined power and refrigeration cycle by the exergy method, Energy 31 (2006) 3401-3414

[16] K. Takeshita, Y. Amano, T. Hashizume, Experimental study of advanced cogeneration with ammonia-water mixture cycles at bottoming, Energy 30 (2005) 247-260

[17] T. Miyazaki, A. Akisawa, T. Kashiwagi, Operating conditions of a three-stage combined power cycle using cold energy for maximizing exergetic efficiency, Trans. Japan Soc. Refriger. Air Cond. Eng. 18 (2011) 173-183

[18] I.O. Marrero, A.M. Lefsaker, A. Razani, K.J. Kim, Second law analysis and optimization of a combined triple power cycle, Energy Convers. Manag. 43 (2002) 557-573

[19] A. Momeni, H. Shokouhmand, Thermodynamic modeling of three-stage combined cycle power systems utilizing ammonia-water mixture as working fluid in bottoming cycle, Int. J. Exergy 14 (2014) 320-340

[20] P. Ahmadi, I. Dincer, M. Rosen Energy and exergy analyses of hydrogen production via solar-boosted ocean thermal energy conversion and PEM electrolysis, Int. J. Hydrogen Energy 38 (2013) 1795-1805

[21] P. Ahmadi, I. Dincer, M. Rosen, Exergy, exergoeconomic and environmental analyses and evolutionary algorithm based multi-objective optimization of combined cycle power plants, Energy 36 (2011) 5886-5898

[22] V. Zare, S.M.S. Mahmoudi, M. Yari, M. Amidpour, Thermoeconomic analysis and optimization of an ammonia-water power/cooling cogeneration cycle, Energy 47 (2012) 271-283
[23] P. Ahmadi, I. Dincer, M. Rosen, Thermodynamic modeling and multi-objective evolutionary-based optimization of a new multigeneration energy system, Energy Convers. Manag. 76 (2011) 282-300

[24] C. Coskun, Z. Oktay, I. Dincer, Investigation of some renewable energy and exergy parameters for two Geothermal District Heating Systems, Int. J. Exergy 8 (2011) 1-15

[25] O. Arslan, Exergoeconomic evaluation of electricity generation by the medium temperature geothermal resource, using a Kalina cycle: Simav case study, Int. J. Thermal Sci. 49 (2010) 1886-1873

[26] W. Fu, J. Zhu, W. Zhang, Z. Lu, Performance evaluation of Kalina cycle subsystem on geothermal generation on the oilfield, Appl. Thermal Eng. 54 (2013) 497-506

[27] O. Singh, S.C. Kaushik, Thermoeconomic evaluation and optimization of a Brayton-Rankine-Kalina combined triple power cycle, Energy Convers. Manag. 71 (2013) $32-42$

[28] P. Ahmadi, M.A. Rosen, I. Dincer, Greenhouse gas emission and exergo-environmental analyses of a trigeneration energy system, Int. J. Green House Gas Control 5 (2011) $1540-9$

[29] P. Ahmadi, I. Dincer, M. Rosen. Development and assessment of an integrated biomass-based multi-generation energy system, Energy 56 (2013) 155-166

[30] M. Ghazi, P. Ahmadi, A.F Sotoodeh, A. Taherkhani. Modeling and thermo-economic optimization of heat recovery heat exchangers using a multimodal genetic algorithm, Energy Convers. Manag. 58 (2012) 149-156

[31] M.S. Peters, K.D. Timmerhaus, Plant Design And Economics For Chemical Engineers, 4th edition, McGraw-Hill, New York, 1991

[32] P. Roosen, S. Uhlenbruck, K. Lucas, Pareto optimization of a combined cycle power system as a decision support tool for trading off investment vs. operating costs, Int. J. Thermal Sci. 42 (2003) 553-560

[33] J.P. Holman, Heat Transfer, 5th edition, McGraw-Hill, New York, 2002

[34] A. Bejan, G. Tsatsaronis, M. Moran, Thermal design and optimization, fifth ed., John Wiley \& Sons, New York, 1999

[35] M. Benali, A. Hammache, F. Aube, J. Dipama, R. Cantave, Dynamic multi objective optimization of largescale industrial production systems: an emerging strategy, Int. J. Energy Res. 31 (2007) 1202-1225

[36] A. Rovira, M. Valdes, J. Casanova, A new methodology to solve non-linear equation systems using genetic algorithms. Application to combined cycle gas turbine simulation, Int. J. Numer. Methods Eng. 63 (2005) 1424-1435 